\title{
Lung adenocarcinoma: Are skip N2 metastases different from non-skip?
}

\author{
Hang Li, MD, ${ }^{\text {a,b }}$ Hong Hu, MD, ${ }^{\text {a,b }}$ Rui Wang, PhD, ${ }^{\text {a,b }}$ Yuan Li, PhD, ${ }^{\text {b,c }}$ Lei Shen, PhD, ${ }^{\text {b,c }}$ \\ Yihua Sun, $\mathrm{PhD},{ }^{\mathrm{a}, \mathrm{b}}$ and Haiquan Chen, $\mathrm{PhD}^{\mathrm{a}, \mathrm{b}}$
}

\section{ABSTRACT}

Objective: This study investigated the association between clinical pathologic features, especially adenocarcinoma subtypes and prognosis, and skip N2 metastasis in patients with lung adenocarcinoma.

Methods: In this study, 177 patients with lung adenocarcinoma and N2 metastasis were enrolled. Patients who had N2 lymph node metastases without N1 lymph node involvement were defined as skip N2 and otherwise as non-skip N2. We investigated the difference of clinicopathologic characteristics, recurrence-free survival, overall survival, and spectrum of well-identified molecular alterations in EGFR, KRAS, HER2, BRAF, ALK, ROS1, and RET genes in the 2 groups.

Results: Skip N2 metastasis was found in 45 patients, in whom a remarkably lower incidence of lymphovascular invasion was revealed $(P=.01)$. Skip N2 metastasis was also associated with acinar subtype, good differentiation, and right lung cancer. The recurrence-free survival and overall survival were significantly better in the skip N2 group (5-year recurrence-free survival $37.4 \%$ vs $5.7 \%$; log-rank $P=.005$; 5-year overall survival $60.7 \%$ vs $32.1 \%$; log-rank $P=.024)$. The predictive value of skip $\mathrm{N} 2$ was more significant in patients with lesions in the right lung (5-year recurrence-free survival $36.6 \%$ vs $0.0 \%$; log-rank $P=.002$; 5-year overall survival $57.2 \%$ vs $27.9 \%$; log-rank $P=.016)$ and in patients whose tumor diameter was no more than $3 \mathrm{~cm}(5-$ year recurrence-free survival $43.1 \%$ vs $6.7 \%$; log-rank $P=.01 ; 5$-year overall survival 74.6 vs $27.6 \%$; log-rank $P=.04)$.

Conclusions: There are distinct differences in clinicopathologic features and prognosis in patients with or without skip N2 metastasis. Considering the results of our study, subclassifications of mediastinal lymph node metastases could have clinical significance for patients with lung adenocarcinoma. (J Thorac Cardiovasc Surg 2015;150:790-5)

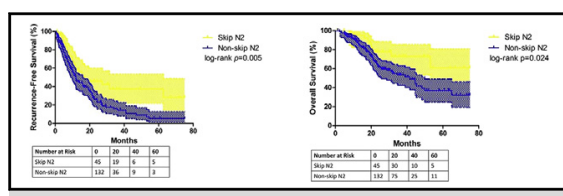

RFS and OS of patients with lung adenocarcinoma with or without skip N2 status.

\section{Central Message}

Patients with skip N2 metastases have more acinar adenocarcinoma subtypes, welldifferentiated metastases, and metastases located in the right lung than patients with non-skip N2. In view of the results of our study, subclassifications of mediastinal lymph node metastases could have clinical significance for patients with lung adenocarcinoma.

\section{Perspective}

Skip N2 is not a rare phenomenon in lung adenocarcinoma cases. Patients with skip N2 metastasis have better survival according to former studies and the current work. However, its predictive value for better clinical outcome is stronger in patients with lesions in the right lung and patients whose tumor diameter is no more than $3 \mathrm{~cm}$. In view of our results, skip N2 should not be recognized as a predictor for better survival in all lung adenocarcinoma cases, but in a more specific group of patients.

See Editorial page 765 .
From the a Department of Thoracic Surgery, Fudan University Shanghai Cancer Center, Shanghai, China; ${ }^{b}$ Department of Oncology, Shanghai Medical College, Fudan University, Shanghai, China; and ${ }^{\mathrm{c}}$ Department of Pathology, Fudan University Shanghai Cancer Center, Shanghai, China.

Funded by the Key Construction Program of the National "985" Project (Grant 985III-YFX0102); National Natural Science Foundation of China (Grants 81330056 and 81372525); Science and Technology Commission of Shanghai Municipality (Program of Shanghai Subject Chief Scientist; Grant 12XD1402000); and Shanghai Hospital Development Center (Grant SHDC12012308).

H.L. and H.H. contributed equally to this work.

Read at the 41st Annual Meeting of The Western Thoracic Surgical Association, Whistler, British Columbia, Canada, June 24-27, 2015.

Received for publication Oct 28, 2014; revisions received March 24, 2015; accepted for publication March 30, 2015; available ahead of print Aug 14, 2015.

Address for reprints: Haiquan Chen, PhD, Department of Thoracic Surgery, Fudan University Shanghai Cancer Center, 270 Dong-An Rd, Shanghai 200032, China (E-mail: hqchen1@yahoo.com).

0022-5223/\$36.00

Copyright (c) 2015 by The American Association for Thoracic Surgery

http://dx.doi.org/10.1016/j.jtcvs.2015.03.067
Non-small cell lung cancer (NSCLC) is the leading cause of cancer-related death in the whole world. ${ }^{1}$ Pathologic $\mathrm{N} 2$ metastasis is defined in NSCLC as metastases to the ipsilateral mediastinal lymph nodes (LNs), and it significantly worsens the prognosis. If a patient is diagnosed with pathologic N2, adjuvant chemotherapy and radiotherapy are recommended by the National Comprehensive Cancer Network guidelines. However, in clinical practice, some patients with NSCLC present mediastinal LN metastases without corresponding peribronchial or ipsilateral hilar region LN involvement, which is called skip N2 metastasis. ${ }^{2,3}$ Skip N2 metastasis occurs in approximately $20 \%$ to $30 \%$ of patients with NSCLC N2, and it is associated with a favorable prognosis. ${ }^{3-6}$ Because mediastinal LN involvement of patients with NSCLC 


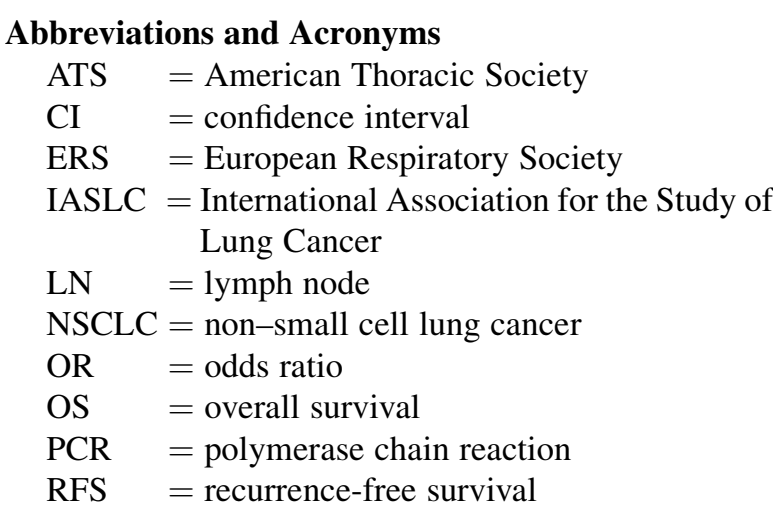

influences the multidisciplinary treatment and patients with skip N2 have a remarkably better clinical outcome, it is crucial to distinguish patients with skip N2 from patients with NSCLC with N2 status.

Adenocarcinoma, which has been considered to be associated with skip N2 metastasis, ${ }^{7}$ is the most prevalent pathologic subtype of diagnosed NSCLC. The new classification for lung adenocarcinoma, which was proposed by the International Association for the Study of Lung Cancer/American Thoracic Society/European Respiratory Society (IASLC/ATS/ERS), has been proved to be related to several clinical features, ${ }^{8,9}$ but its effect on skip metastasis has not been discussed. Therefore, we performed this retrospective study on patients with lung adenocarcinoma with or without pathologic skip N2 metastasis, aiming to further elucidate the clinical significance and prognostic value of skip N2.

\section{MATERIAL AND METHODS Patients}

Patients with primary diagnosed NSCLC were consecutively enrolled from September 2009 to September 2011. Inclusion criteria for this study were the following: (1) Patients underwent R0 resection and systematic ipsilateral mediastinal lymphadenectomy; (2) a re-review of the pathologic diagnosis of adenocarcinoma was confirmed by 2 pathologists; (3) each LN was examined with consecutive sections; and (4) patients were proved to have N2 status and received 4-cycle cisplatin-based adjuvant chemotherapy. The stations of N1 and N2 were determined according to the description proposed by the IASLC. ${ }^{10}$ Skip N2 was defined as patients with N2 LN metastases without N1 LN involvement. Single N2 was defined as patients who had only 1 station mediastinal LN involvement, and otherwise as multiple N2. Patients who received any neoadjuvant chemotherapy or radiotherapy were excluded (Figure 1). Written informed consent was received from all enrolled patients. This study was approved by the ethics committee in Fudan University Shanghai Cancer Center.

\section{Clinical and Pathologic Features}

Clinical and pathologic characteristics, which were collected from the medical history system at the Fudan University Shanghai Cancer Center, included sex, smoking history, age at diagnosis, tumor size and differentiation, lymphovascular and pleura invasion, tumor location, and adenocarcinoma subtypes according to the IASLC/ATS/ERS multidisciplinary classification. ${ }^{11}$ Contrast chest computed tomography, brain magnetic resonance imaging, bone emission computed tomography, and abdominal ultrasound were performed for preoperative staging. These examinations were also performed postoperatively to detect local recurrence or metastases in other organs. Patients were contacted every 3 months after the date of diagnosis in clinic or by telephone about disease recurrence and survival information. The median follow-up phase was 48.5 months for the skip N2 group and 52.8 months for the non-skip N2 group. Recurrence-free survival (RFS) was calculated from the date of diagnosis and date of recurrence or last follow-up. Overall survival (OS) was defined as the time elapsed between the date of diagnosis and the date of death or last follow-up.

\section{Mutation and Gene Fusion Analysis}

EGFR (exons 18 to 21), KRAS (exons 2 to 3), HER2 (exons 18 to 21), $B R A F$ (exons 11 to 15), and PIK3CA (exon 9 and exon 20) were amplified by polymerase chain reaction (PCR) using complementary DNA as previously described. ${ }^{8}$ A combined strategy of quantitative real-time PCR and reverse transcriptase PCR was performed to assess ALK, ROS1, and RET fusion, with validation using fluorescence in situ hybridization as previously described. ${ }^{12}$

\section{Statistical Analyses}

We adopted Pearson chi-square test or Fisher exact tests to assess the correlations between clinicopathologic variables and patterns of $\mathrm{LN}$ metastases. For the characteristics, which were proved to be significantly associated with skip N2 in univariate analysis, binary logistic regression model was used to test their odds ratios (ORs). Survival curves were made using the Kaplan-Meier method. RFS and OS were compared using log-rank test. Cox proportional hazards regression was applied to analyze the ORs of these risk factors including the skip N2 phenomenon (present vs absent), LN metastasis (single station vs multiple stations), tumor size ( $\leq 3 \mathrm{vs}>3$ $\mathrm{cm}$ ), and lesion location (right vs left), using a likelihood forward stepwise selection model. The statistical analyses were performed using SPSS 16.0 for Windows (SPSS Inc, Chicago, Ill). All the tests were 2 tailed.

\section{RESULTS}

\section{Patient Characteristics}

A total of 177 patients, with tumors ranging from 0.6 to 9 $\mathrm{cm}$, were included. Some $48 \%$ of patients had a tumor in the left lung, and $52 \%$ of patients had a tumor in the right lung. Lobectomy was performed in 152 patients, wedge resection was performed in 17 patients, sleeve lobectomy was performed in 2 patients, and pneumonectomy was performed in 6 patients. The other characteristics, including sex, age, smoking history, lymphovascular or pleura invasion, lesion location, differentiation, and adenocarcinoma subtypes, are listed in Table 1.

\section{Correlation Between Skip N2 and Clinicopathologic Features}

In the 177 patients, skip N2 occurred in $45(25.4 \%)$. Through further comparison of the clinical pathologic variables between skip N2 and non-skip N2 cases, we found a remarkably lower incidence of lymphovascular invasion in those with skip N2 lung adenocarcinoma $(P=.01)$. Meanwhile, a lower incidence of pleura invasion was also found in these patients, but it did not reach statistical significance $(P=.07)$. We also investigated the association 


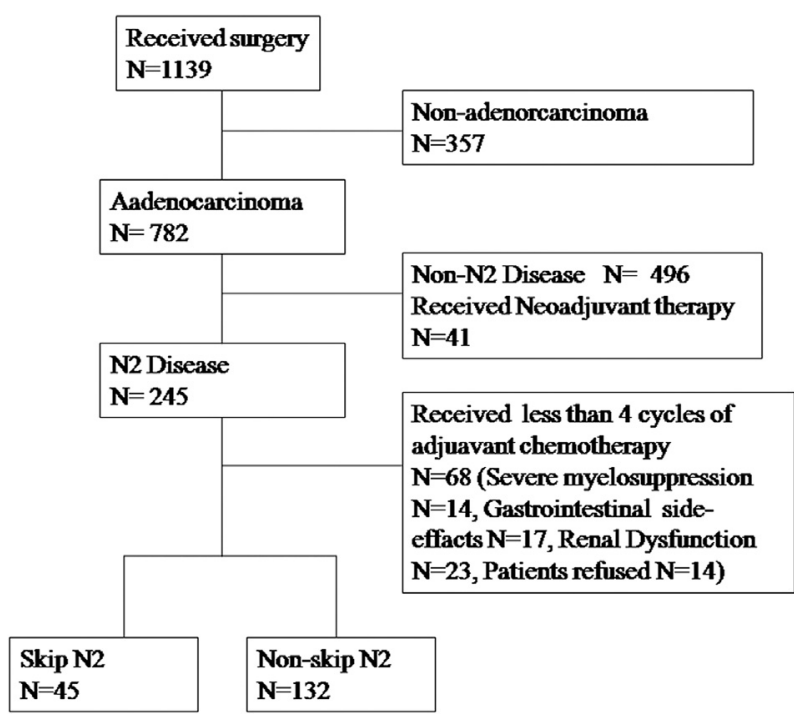

FIGURE 1. Process of patient enrollment.

between tumor location and LN status. Skip N2 occurred more frequently in patients with a lesion in the right lung $(P=.02)$. No remarkable difference was found in age at diagnosis and gender between the 2 categories, or in smoking history and tumor size (Table 2).

According to the IASLC/ATS/ERS multidisciplinary classification of lung adenocarcinoma, we recorded the predominant subtypes of these $177 \mathrm{~N} 2$ adenocarcinoma cases. Skip N2 metastasis occurred more frequently in patients with acinar-predominant subtype $(P=.004)$, whereas the incidence of non-skip N2 was significantly higher in those with papillary-predominant subtype $(P=.015)$. The frequency of skip N2 did not remarkably vary from other adenocarcinoma subtypes (Table 2).

In the 177 patients, 94 (53.1\%) EGFR mutations and 11 $(6.2 \%) K R A S$ mutations were found. Information on the mutational status of other genes is listed in Table 2. Considering the common driver genes involved in our study, the incidence of molecular alterations did not significantly vary with LN metastases pattern (Table 2).

Correlations between the skip N2 metastasis and the clinicopathologic features were further evaluated by logistic regression analysis, including lymphovascular invasion, differentiation, adenocarcinoma subtype, and lesion location. Absence of lymphovascular invasion (OR, 1.67, 95\% confidence interval [CI], 1.04-2.72; $P=.02$ ), acinar subtype (OR, $2.53,95 \% \mathrm{CI}, 1.39-4.37 ; P=.01$ ), and right lung cancer $(\mathrm{OR}, 1.78,95 \% \mathrm{CI}, 1.16-3.25 ; P=.02)$ were independently associated with skip N2 metastasis.

\section{Skip N2 and Clinical Prognosis}

We further investigated the difference of clinical outcome between patients with skip N2 and non-skip N2.
TABLE 1. Clinicopathologic and molecular features of patients

\begin{tabular}{|c|c|c|}
\hline Variables & No & $\%$ \\
\hline \multicolumn{3}{|l|}{ Sex } \\
\hline Male & 96 & 54.2 \\
\hline Female & 81 & 45.8 \\
\hline \multicolumn{3}{|l|}{ Age } \\
\hline$\geq 60 y$ & 117 & 66.1 \\
\hline$<59$ y & 60 & 33.9 \\
\hline \multicolumn{3}{|l|}{ Smoking history } \\
\hline Smoker & 75 & 42.4 \\
\hline Never & 102 & 57.6 \\
\hline \multicolumn{3}{|l|}{ Tumor size } \\
\hline$\leq 3 \mathrm{~cm}$ & 92 & 52.0 \\
\hline$>3 \mathrm{~cm}$ & 85 & 48.0 \\
\hline \multicolumn{3}{|c|}{ Lymphovascular invasion } \\
\hline+ & 59 & 33.3 \\
\hline- & 118 & 66.7 \\
\hline \multicolumn{3}{|l|}{ Pleura invasion } \\
\hline+ & 114 & 64.4 \\
\hline- & 63 & 35.6 \\
\hline \multicolumn{3}{|l|}{ Differentiation } \\
\hline Well & 10 & 5.6 \\
\hline Moderate & 122 & 68.9 \\
\hline Poor & 45 & 25.4 \\
\hline \multicolumn{3}{|c|}{ Adenocarcinoma subtype } \\
\hline Acinar & 74 & 41.8 \\
\hline Papillary & 34 & 19.2 \\
\hline Solid & 50 & 28.2 \\
\hline IMA & 12 & 6.8 \\
\hline MP & 7 & 4.0 \\
\hline \multicolumn{3}{|l|}{ Lesion location } \\
\hline Left & 85 & 48.0 \\
\hline Right & 92 & 52.0 \\
\hline \multicolumn{3}{|l|}{ Left lung } \\
\hline Upper lobe & 53 & 29.9 \\
\hline Lower lobe & 32 & 18.1 \\
\hline \multicolumn{3}{|l|}{ Right lung } \\
\hline Upper lobe & 40 & 22.6 \\
\hline Middle lobe & 16 & 9.0 \\
\hline Lower lobe & 36 & 20.3 \\
\hline
\end{tabular}

The RFS and OS were significantly better in the skip N2 group (5-year RFS; $37.4 \%$ vs $5.7 \%$; log-rank $P=.005$; 5-year OS; $60.7 \%$ vs $32.1 \%$; log-rank $P=.024$ ) (Figure 2). Skip N2 was found to be a better prognosis predictor in patients with tumor diameter no more than $3 \mathrm{~cm}$ (5-year RFS; $43.1 \%$ vs $6.7 \%$; log-rank $P=.01 ; 5$-year OS; 74.6 vs $27.6 \%$; log-rank $P=.04$ ) (Figure $3, A$ and $B$ ), but it had no predictive significance in patients whose tumor diameter was more than $3 \mathrm{~cm}$. The predictive value of skip $\mathrm{N} 2$ was more significant in patients with a lesion in the right lung (5-year RFS; $36.6 \%$ vs $0.0 \%$; log-rank $P=.002 ; 5$-year OS; $57.2 \%$ vs $27.9 \%$; log-rank $P=.016$ ) (Figure 3, $C$ and $D$ ). In further comparison, we divided patients into the single station $\mathrm{N} 2$ group and 
TABLE 2. Clinicopathologic and molecular features of patients with or without skip $\mathbf{N} 2$

\begin{tabular}{|c|c|c|c|}
\hline Variables & $\begin{array}{l}\text { Skip N2 } \\
(\mathrm{n}=45)\end{array}$ & $\begin{array}{c}\text { Non-skip N2 } \\
(\mathbf{n}=132)\end{array}$ & $P$ value \\
\hline $\begin{array}{l}\text { Mean No. of dissected } \\
\text { LNs }\end{array}$ & $22.3 \pm 3.2$ & $20.7 \pm 2.8$ & .83 \\
\hline \multicolumn{4}{|l|}{ Sex } \\
\hline Male & $20(44.44 \%)$ & $76(57.58 \%)$ & \multirow[t]{2}{*}{.127} \\
\hline Female & $25(55.56 \%)$ & $56(42.42 \%)$ & \\
\hline \multicolumn{4}{|l|}{ Age } \\
\hline Mean & $56.9 \pm 1.6$ & $56.1 \pm 1.4$ & .675 \\
\hline$\geq 60 \mathrm{y}$ & $32(71.11 \%)$ & $85(64.39 \%)$ & \multirow[t]{2}{*}{.09} \\
\hline$<59 \mathrm{y}$ & $13(28.89 \%)$ & $47(35.61 \%)$ & \\
\hline \multicolumn{4}{|l|}{ Smoking history } \\
\hline Smoker & $17(37.78 \%)$ & $58(43.94 \%)$ & \multirow[t]{2}{*}{.47} \\
\hline Never & $28(62.22 \%)$ & $74(56.06 \%)$ & \\
\hline \multicolumn{4}{|l|}{ Tumor size } \\
\hline Mean & $3.56 \pm 0.25$ & $3.57 \pm 0.15$ & .96 \\
\hline$\leq 3 \mathrm{~cm}$ & $25(55.56 \%)$ & $67(50.76 \%)$ & \multirow[t]{2}{*}{.578} \\
\hline$>3 \mathrm{~cm}$ & $20(44.44 \%)$ & $65(49.24 \%)$ & \\
\hline \multicolumn{4}{|l|}{ Lymphovascular invasion } \\
\hline+ & $8(17.78 \%)$ & $51(38.64 \%)$ & \multirow[t]{2}{*}{$.01 *$} \\
\hline- & $37(82.22 \%)$ & $81(61.36 \%)$ & \\
\hline \multicolumn{4}{|l|}{ Pleura invasion } \\
\hline+ & $24(53.33 \%)$ & $90(68.18 \%)$ & \multirow[t]{2}{*}{.078} \\
\hline- & $21(46.67 \%)$ & $42(31.82 \%)$ & \\
\hline \multicolumn{4}{|l|}{ Mutational status } \\
\hline$E G F R$ & $25(55.56 \%)$ & $69(52.27 \%)$ & .703 \\
\hline$K R A S$ & $3(6.67 \%)$ & $8(6.06 \%)$ & .884 \\
\hline$H E R 2$ & $3(6.67 \%)$ & $5(3.79 \%)$ & .421 \\
\hline$B R A F$ & $1(2.22 \%)$ & $3(2.27 \%)$ & 1 \\
\hline$A L K$ & $0(0 \%)$ & $5(3.79 \%)$ & .331 \\
\hline $\operatorname{ROS} 1$ & $0(0 \%)$ & $3(2.27 \%)$ & .572 \\
\hline RET & $0(0 \%)$ & $5(3.79 \%)$ & .331 \\
\hline Pan-negative & $13(28.89 \%)$ & $34(25.76 \%)$ & .699 \\
\hline \multicolumn{4}{|l|}{ Differentiation } \\
\hline Well & $7(15.56 \%)$ & $3(2.27 \%)$ & $.003^{*}$ \\
\hline Moderate & $27(60.00 \%)$ & $95(71.97 \%)$ & .134 \\
\hline Poor & $11(24.44 \%)$ & $34(25.76 \%)$ & .861 \\
\hline \multicolumn{4}{|l|}{ Adenocarcinoma subtype } \\
\hline Acinar & $27(60.00 \%)$ & $47(35.61 \%)$ & $.004 *$ \\
\hline Papillary & $3(6.67 \%)$ & $31(23.48 \%)$ & .015 \\
\hline Solid & $11(24.44 \%)$ & $39(29.55 \%)$ & .512 \\
\hline IMA & $4(8.89 \%)$ & $8(6.06 \%)$ & .504 \\
\hline MP & $0(0 \%)$ & $7(5.30 \%)$ & .194 \\
\hline \multicolumn{4}{|l|}{ Lesion location } \\
\hline Left & $15(33.33 \%)$ & $70(53.03 \%)$ & \multirow[t]{2}{*}{$.022^{*}$} \\
\hline Right & $30(66.67 \%)$ & $62(46.97 \%)$ & \\
\hline \multicolumn{4}{|l|}{ Left lung } \\
\hline Upper lobe & $12(80 \%)$ & $41(58.57 \%)$ & \multirow[t]{2}{*}{.15} \\
\hline Lower lobe & $3(20 \%)$ & $29(41.43 \%)$ & \\
\hline \multicolumn{4}{|l|}{ Right lung } \\
\hline Upper lobe & $14(46.67 \%)$ & $26(41.94 \%)$ & .668 \\
\hline Middle lobe & $7(23.33 \%)$ & $9(14.52 \%)$ & .296 \\
\hline Lower lobe & $9(30 \%)$ & $27(43.54 \%)$ & .212 \\
\hline
\end{tabular}

$L N$, Lymph node; IMA, invasive mucinous adenocarcinoma; $M P$, micropapillary. *Compared with all the other cases. multiple stations N2 group. Patients who had skip single N2 metastasis had the best clinical outcome in the 4 groups (5year RFS; $34.4 \%$; log-rank $P=.001 ; 5$-year OS; 64.3\%; $\log$-rank $P=.006$ ) (Figure $3, E$ and $F$ ). We also investigated the predictive significance of lung adenocarcinoma subtype in the N2 group. No remarkable difference was found between patients with different subtypes (log-rank $P=.179)$. In multivariate analysis, skip N2 retained its predictive significance for better RFS (OR, 0.493; 95\% CI, $0.314-0.773, P=.002$ ), but had no significance for predicting OS. Single N2 metastasis also was an independent predictor for better RFS (OR, 0.346; 95\% CI, 0.128-0.633, $P=.001)$ and OS (OR, 0.429; 95\% CI, 0.237-0.751, $P=.004)$.

\section{DISCUSSION}

In the last decade, a number of studies have reported that the incidence of skip N2 in patients with NSCLC N2 ranges from $19.5 \%$ to $36 \% .{ }^{13-15}$ Skip N2 seems to be an important subgroup of $\mathrm{N} 2$ cases, because it is not a rare phenomenon in NSCLC and patients with skip N2 were proved to have different clinical features and outcome. ${ }^{16,17}$ In this series, we investigate the clinical variables associated with patients with lung adenocarcinoma having skip N2. To the best of our knowledge, there is no similar study that has revealed the association between adenocarcinoma subtypes and skip N2 metastasis.

In our study, we found that the frequency of skip N2 in patients with acinar- predominant adenocarcinoma was remarkably high, and in those with papillary- predominant subtype it was significantly low. In previous work, ${ }^{18}$ we demonstrated the association between papillary subtype and lymphovascular invasion. Hilar LNs may be involved first through lymphovascular invasion, and this finding may explain the higher incidence of continuous N2 metastasis in the papillary predominant subtype. Warth and colleagues $^{19}$ revealed that pathologic N2 status correlated with the acinar subtype of lung adenocarcinoma. In our series, $36.5 \%$ of acinar cases were skip N2 status, which is significantly higher than the overall incidence of skip N2 in other adenocarcinoma subtypes. No previous study has focused on the correlation between acinar subtype and skip N2 metastasis.

We further investigated the relationship between lesion location and skip N2 phenomenon. In this series, we found a higher incidence of skip N2 in right lung cancer, but there was no association between upper, middle, and lower right lobe cancer and skip N2. Riquet and colleagues ${ }^{20}$ investigated the lymphatic drainage of different sides of lung to the mediastinal LNs in cadavers. Similar percentages of direct drainage occurrence to the mediastinal nodes were found in the right and left lungs. Some investigations 

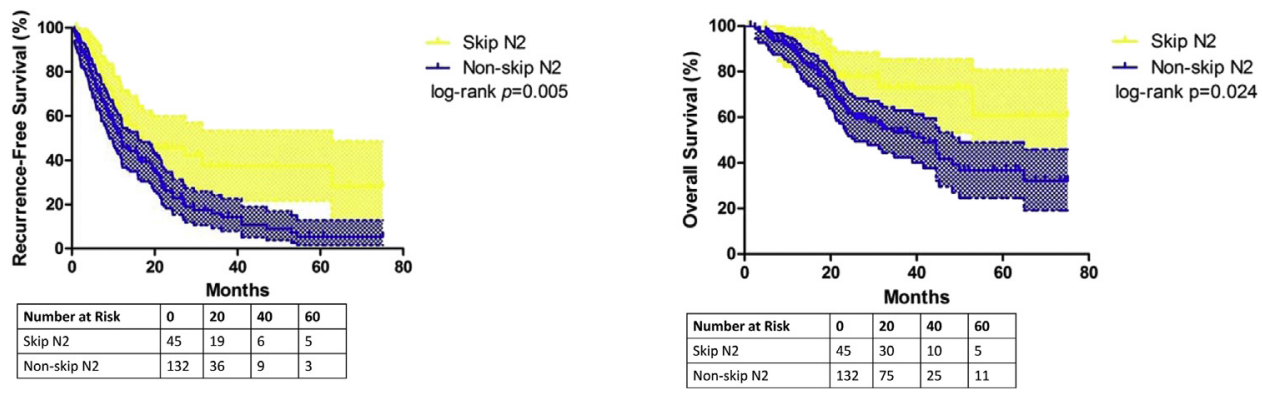

FIGURE 2. RFS and OS of patients with lung adenocarcinoma with or without skip N2 status.

performed in patients showed a higher occurrence rate of direct drainage in the right lung. ${ }^{21,22}$ Our current results also verified this difference of lymphatic drainage between right and left lung cancers. This result emphasized the need for complete dissection of the mediastinal LNs in right lung adenocarcinoma, and no enlarged hilar LNs were found in the preoperative imaging examinations.
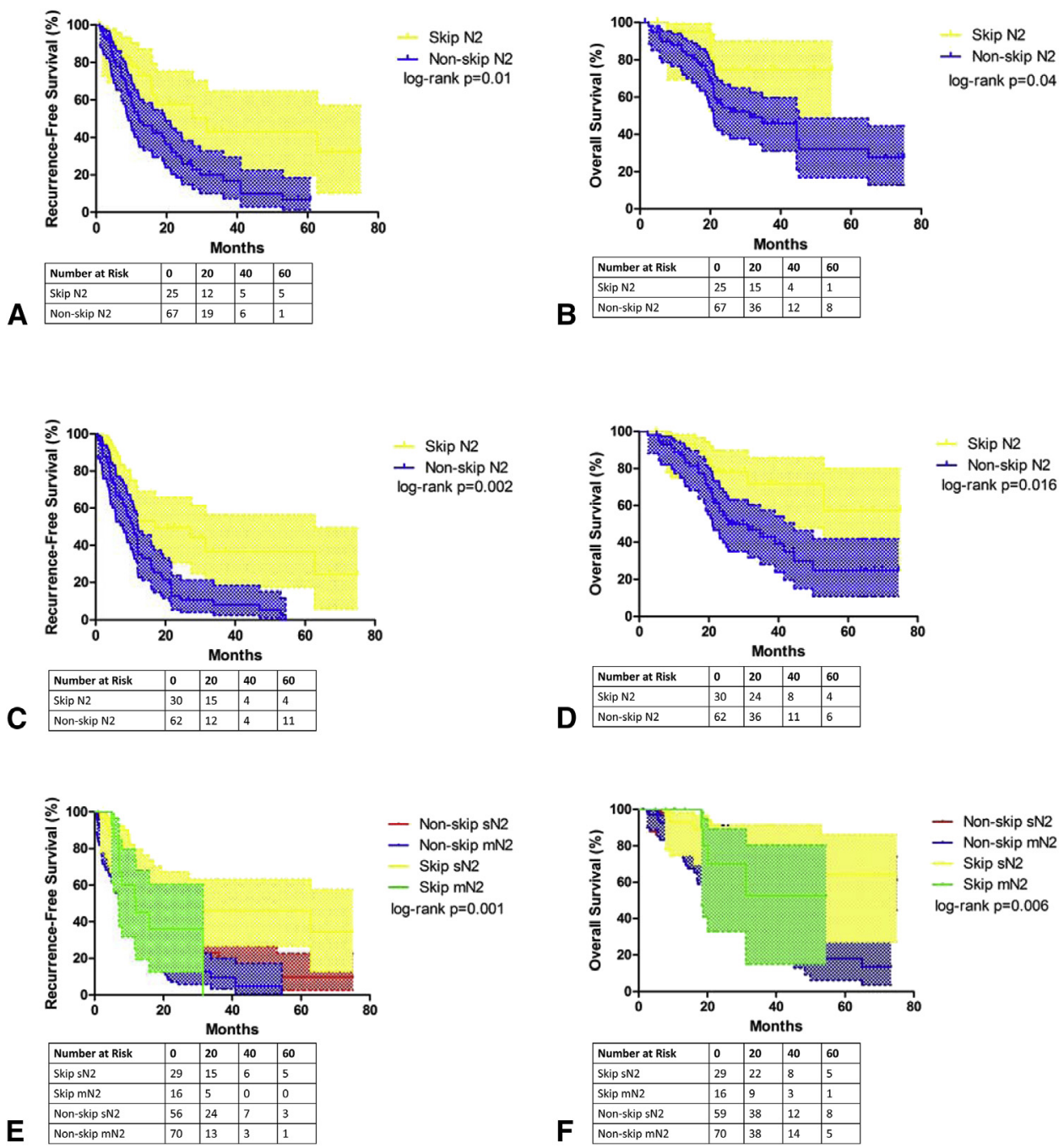

FIGURE 3. RFS (A) and OS (B) of patients with tumor diameter no more than $3 \mathrm{~cm}$ with or without skip N2 status. RFS (C) and OS (D) of patients with right lung cancer with or without skip N2 metastasis. RFS (E) and OS (F) of patients with single or multiple N2 metastasis. $m N 2$, Multiple stations N2 metastasis; $s N 2$, single station N2 metastasis. 
Many previous studies have demonstrated a favorable prognosis of patients with skip N2. ${ }^{3,23,24}$ The results of our series also confirmed these findings, especially in patients whose tumor diameter was no more than $3 \mathrm{~cm}$. When classifying the patients by lesion location, the predictive value of skip N2 is more significant in right lung adenocarcinoma. Considering these results, skip N2 should be taken as a predictor for a better prognosis in particular subgroups of patients. However, further perspective investigations could be performed to demonstrate the prognostic significance of skip N2 phenomenon in patients with lung adenocarcinoma.

\section{Study Limitations}

Our work is a retrospective study, and the number of patients with skip N2 is relatively small. With continuous collection of patients and clinical data, more detailed and precise results may be revealed in the future. A randomized trial should be designed to validate the findings of our work.

\section{CONCLUSIONS}

We found that the incidence of skip N2 was significantly associated with acinar subtype, lesion location in the right lung, and good differentiation in patients with lung adenocarcinoma. There was also a distinct clinical prognosis between patients with or without skip N2 metastasis. In view of the results of our study and previous investigations, subclassifications of mediastinal LN metastases could have clinical significance for patients with lung adenocarcinoma.

\section{Conflict of Interest Statement}

Authors have nothing to disclose with regard to commercial support.

The authors thank Qiong Lu, Jie Xu, and Youjia Deng for technical support.

\section{References}

1. Cancer statistics. JAMA. 2013;310:982

2. Tateishi M, Fukuyama Y, Hamatake M, Kohdono S, Ishida T, Sugimachi K. Skip mediastinal lymph node metastasis in non-small cell lung cancer. J Surg Oncol. 1994;57:139-42.

3. Riquet M, Assouad J, Bagan P, Foucault C, Le Pimpec Barthes F, Dujon A, et al. Skip mediastinal lymph node metastasis and lung cancer: a particular N2 subgroup with a better prognosis. Ann Thorac Surg. 2005;79:225-33.

4. Yoshino I, Yokoyama H, Yano T, Ueda T, Takai E, Mizutani K, et al. Skip metastasis to the mediastinal lymph nodes in non-small cell lung cancer. Ann Thorac Surg. 1996;62:1021-5.

5. Misthos P, Sepsas E, Athanassiadi K, Kakaris S, Skottis I. Skip metastases: analysis of their clinical significance and prognosis in the IIIA stage of non-small cell lung cancer. Eur J Cardiothorac Surg. 2004;25:502-8.
6. Benoit L, Anusca A, Ortega-Deballon P, Cheynel N, Bernard A, Favre JP. Analysis of risk factors for skip lymphatic metastasis and their prognostic value in operated N2 non-small-cell lung carcinoma. Eur J Surg Oncol. 2006;32:583-7.

7. Okada M, Tsubota N, Yoshimura M, Miyamoto Y. Proposal for reasonable mediastinal lymphadenectomy in bronchogenic carcinomas: role of subcarinal nodes in selective dissection. J Thorac Cardiovasc Surg. 1998;116:949-53.

8. Li H, Pan Y, Li Y, Li C, Wang R, Hu H, et al. Frequency of well-identified oncogenic driver mutations in lung adenocarcinoma of smokers varies with histological subtypes and graduated smoking dose. Lung Cancer. 2013;79:8-13.

9. Mansuet-Lupo A, Bobbio A, Blons H, Becht E, Ouakrim H, Didelot A, et al. The new histological classification of lung primary adenocarcinoma subtypes is a reliable prognostic marker and identifies tumors with different mutation status: the experience of a French cohort. Chest. 2014;146:633-43.

10. Rusch VW, Asamura H, Watanabe H, Giroux DJ, Rami-Porta R, Goldstraw P. The IASLC lung cancer staging project: a proposal for a new international lymph node map in the forthcoming seventh edition of the TNM classification for lung cancer. J Thorac Oncol. 2009;4:568-77.

11. Travis WD, Brambilla E, Noguchi M, Nicholson AG, Geisinger KR, Yatabe Y, et al. International Association for the Study of Lung Cancer/American Thoracic Society/European Respiratory Society international multidisciplinary classification of lung adenocarcinoma. J Thorac Oncol. 2011;6:244-85.

12. Wang R, Hu H, Pan Y, Li Y, Ye T, Li C, et al. RET fusions define a unique molecular and clinicopathologic subtype of non-small-cell lung cancer. J Clin Oncol. 2012;30:4352-9.

13. Kotoulas CS, Foroulis CN, Kostikas K, Konstantinou M, Kalkandi P, Dimadi M et al. Involvement of lymphatic metastatic spread in non-small cell lung cancer accordingly to the primary cancer location. Lung Cancer. 2004;44:183-91.

14. Gorai A, Sakao Y, Kuroda H, Uehara H, Mun M, Ishikawa Y, et al. The clinicopathological features associated with skip N2 metastases in patients with clinical stage IA non-small-cell lung cancer. Eur J Cardiothorac Surg. 2015;47:653-8.

15. Saeteng S, Tantraworasin A, Euathrongchit J, Lertprasertsuke N, Wannasopha Y Nodal involvement pattern in resectable lung cancer according to tumor location. Cancer Manag Res. 2012;4:151-8.

16. Prenzel KL, Monig SP, Sinning JM, Baldus SE, Gutschow CA, Grass G, et al Role of skip metastasis to mediastinal lymph nodes in non-small cell lung cancer. J Surg Oncol. 2003;82:256-60.

17. Gunluoglu Z, Solak O, Metin M, Gurses A. The prognostic significance of skip mediastinal lymphatic metastasis in resected non-small cell lung cancer. Eur J Cardiothorac Surg. 2002;21:595.

18. Zhang Y, Sun Y, Xiang J, Hu H, Chen H. A clinicopathologic prediction model for postoperative recurrence in stage Ia non-small cell lung cancer. J Thorac Cardiovasc Surg. 2014;148:1193-9.

19. Warth A, Muley T, Meister M, Stenzinger A, Thomas M, Schirmacher P, et al The novel histologic International Association for the Study of Lung Cancer/ American Thoracic Society/European Respiratory Society classification system of lung adenocarcinoma is a stage-independent predictor of survival. J Clin Oncol. 2012;30:1438-46.

20. Riquet M, Hidden G, Debesse B. Direct lymphatic drainage of lung segments to the mediastinal nodes. An anatomic study on 260 adults. J Thorac Cardiovasc Surg. 1989;97:623-32.

21. Tsubota N, Yoshimura M. Skip metastasis and hidden N2 disease in lung cancer: how successful is mediastinal dissection? Surg Today. 1996;26:169-72.

22. Ilic N, Petricevic A, Arar D, Kotarac S, Banovic J, Ilic NF, et al. Skip mediastinal nodal metastases in the IIIa/N2 non-small cell lung cancer. J Thorac Oncol. 2007; 2:1018-21.

23. Prenzel KL, Baldus SE, Monig SP, Tack D, Sinning JM, Gutschow CA, et al. Skip metastasis in nonsmall cell lung carcinoma: predictive markers and isolated tumor cells in N1 lymph nodes. Cancer. 2004;100:1909-17.

24. Sonobe M, Date H, Wada H, Okubo K, Hamakawa H, Teramukai S, et al. Prognostic factors after complete resection of pN2 non-small cell lung cancer. $J$ Thorac Cardiovasc Surg. 2013;146:788-95.

Key Words: lung adenocarcinoma, lymph node metastasis, survival 